\title{
СРЕДСТВА ФОРМИРОВАНИЯ СОЦИОКУЛЬТУРНОЙ КОМПЕТЕНЦИИ СТУДЕНТОВ-РУСИСТОВ В РАМКАХ ЗАНЯТИЙ ПО ПРАКТИКУМУ РУССКОГО ЯЗЫКА
}

\author{
VARIOUS MEANS OF DEVELOPING SOCIOCULTURAL COMPETENCE \\ BY BA STUDENTS OF RUSSIAN STUDIES \\ (WITHIN THE FRAMEWORK OF INTEGRATED SKILLS \\ IN RUSSIAN CLASSES)
}

МАРИЯ КОССАКОВСКА-МАРАС

\begin{abstract}
This article discusses various ways of developing sociocultural competence in students who learn Russian as a foreign language. These ways of building up students' sociocultural competence serve as sources of knowledge about the other culture. Two basic groups of factors that determine the development of sociocultural competence are shown, i.e. those that are present in the classroom and those that exist after classes. The author pays attention to students' attitude toward the subject matter of what is taught, i.e. their independence, initiative as well as active participation in the teaching process.
\end{abstract}

Maria Kossakowska-Maras, Uniwersytet Rzeszowski, Rzeszów - Polska.

Одной из целей современного образования является приобщение учащихся к культуре изучаемого языка и их подготовка к эффективному участию в диалоге культур. Культурообразующая концепция обучения иностранным языкам в качестве цели обучения выдвигает межкультурную (социальную) компетенцию, согласно которой процесс обучения должен превратиться в межкультурное обучение, в обучение „пониманию чужого", направленное на преодоление ксенофобии, существующих стереотипов, а также на воспитание толерантности к представителям других культур.

Так понимаемое межкультурное обучение включает различные компоненты:

- языковой: лексика, грамматика, речевые образцы и т. д.;

- исторический: различия в оценке прошлого обеих стран;

- практический: правила, необходимые для ориентации в стране;

- эстетический: различия в стиле жизни, одежде и т. п.;

- этический: различия в нормах поведения;

- „стереотипный”: сложившиеся стереотипы в отношении собственной культуры. 
Развитие социокультурной компетенции не является самоцелью, оно тесно связано со стратегическими задачами языкового образования как целостного изучения языковой культуры. ИЯ как средство общения, важнейший компонент культуры, способ видения и организации жизни народа является вместе с тем средством проникновения в инокультурный мир, средством понимания менталитета народов - носителей данного языка. При этом смыслом преподавания ИЯ является введение учащихся в мир иной культуры, иной структуры мышления средствами языка.

Необходимо отметить, что речь идет не об усвоении иной культуры, а об осмысленной попытке понять менталитет народа страны изучаемого языка, о самоопределении учащихся. Все это важно в процессе становления личности, формирования мировоззрения и культурного развития учащихся.

В процессе межкультурного обучения учащиеся, выходя за границы своей собственной культуры, не „уходят" из нее, т. е. не происходит процесс аккультурации или ассимиляции, забвения собственной культуры. Мужкультурное обучение - это образовательный процесс, в ходе которого возникает некая третья культура, являющаяся итогом культурных удалений и сближений${ }^{1}$.

Обучение становится эффективнее при сопоставительном изучении родного языка и родной культуры и ИЯ и культуры другого народа. Это способствует возможности представлять свою страну и культуру в условиях иноязычного общения.

Концепт социокультурной компетенции занимает центральное место в теории межкультурной коммуникации. Социокультурная компетенция включает три блока знаний: лингвострановедческий, социально-психологический и культурологический. Являясь одной из субкомпетенций коммуникативной компетенции, социокультурная компетенция представляет собой знание социокультурного контекста, в котором используется язык. Термин „социокультурная компетенция" в научной литературе определяется как „знания учащимися национально-культурных особенностей стран изучаемого иностранного языка, умения осуществлять речевое поведение в соответствии с этими знаниями, а также готовность и способность жить и взаимодействовать в современном поликультурном мире" 2 .

Учащиеся должны быть не только ознакомлены со страноведческой тематикой, но и быть включены в активный диалог культур. Это

1 См. А.А. Б е р д и ч е в с к и й, Современные тенденции В обучении иностранному языку в Ebpone, „Русский язык за рубежом” 2002, № 2, с. 60-65.

${ }^{2}$ В.В. С а ф о н о в а, Изучение языков международного общения в контексте диалога культур и циивилизаций, Воронеж 1996, с. 25. 
возможно при существенном влиянии учителя / преподавателя, который выступает в роли организатора обучения, партнера по общению и фасилитатора, а также в определенной языковой среде. Самым эффективным средством развития социокультурной компетенции является пребывание в стране изучаемого языка и погружение в атмосферу культуры, традиций, обычаев, социальных норм и т. п. страны изучаемого языка.

Отсутствие языкового барьера не всегда дает возможность полностью понимать собеседника. Возможен обмен информацией, произношение отдельных фраз, реплик, но нет полного понимания. Причиной является прежде всего отсутствие социокультурной компетенции, сформирование которой является необходимым условием успешной коммуникации в современном мире.

Имеется большое количество средств для формирования социокультурной компетенции при переходе общества на информационную ступень развития. Среди них можно выделить средства, связанные с творческой образовательной средой:

- УМК (учебно-методические комплексы), МОК (мультимедийно-обучающие комплексы) и ИКТ (информационно-коммуникативная технология);

- медиатека, библиотека, медиа-библиотека;

- кабинет, мультимедиа-лингафонный компьютерный класс,

и средства языковой парасреды: аутентичные УМК; журналы и газеты; письма; фотографии; предметы быта; аудиовизуальные материалы (фильмы, песни, аудиозаписи и т. п.).

Ниже дается краткая характеристика средств, используемых при формировании социокультурной компетенции.

\section{Средства, связанные с творческой образовательной средой}

1. УМК (учебно-методические комплексы), МОК (мультимедийнообучающие комплексы) и ИКТ (информационно-коммуникативная технология)

Все перечисленные выше компоненты взаимосвязаны. Студент, пользуясь учебно-методическими комплексами, мультимедийно-обучающими комплексами, современными мультимедиа-учебниками, различными традиционными (т. е. на бумажных носителях) учебниками и пособиями, может пользоваться информационно-коммуникативными технологиями, т.е. электронными учебниками, мультимедийными словарями и энциклопедиями, а также текстовыми редакторами, системами мультимедиа, системами мультимедийной презентации, системами дистанционного обучения и Интернет-ресурсами. Значи- 
тельная часть учебных материалов, в том числе тексты источников, комплекты иллюстраций, карты, таблицы, все чаще размещаются не на полиграфических, а на мультимедийных носителях. Многие средства и объекты материально-технического обеспечения являются взаимозаменяемыми.

Самым современным и перспективным видом дидактического материала является МУЛЬТИМЕДИА-УЧЕБНИК. Обучающие программы, разработанные на основе технологий мультимедиа и гипертекста, в языковом образовании уже сегодня начинают составлять серьезную конкуренцию учебным материалам на бумажных носителях, так как включают в себя все необходимые для обучения компоненты (значительно бо́льшие по объему текстотеки на изучаемом языке, словари и справочники, комплекты интерактивных таблиц, тренажеры и практикумы с обновляемыми заданиями, тестовые системы, звук, графику, анимацию, видео) и возможности (открытость для обновления и перенаполнения, интеграция в глобальные сети). Кроме того, благодаря своей интерактивности, нелинейности, динамичности они отвечают потребностям и образу мышления молодого поколения, привыкшего получать сведения не столько из книг, сколько из средств электронной информации и коммуникации: телевизора, видео, компьютера.

Следует отметить, что в учебных материалах, доступных студентам в Польше, социокультурная информация является только одним из элементов, которые находятся в учебных пособиях. Социокультурная компетенция формируется одновременно с коммуникативной и языковой компетенциями. От организатора обучения (т. е. от преподавателя) зависит, как и где будут расставлены акценты в процессе обучения данному языку.

Студенты могут приобретать учебные материалы непосредственно в книжных магазинах в Польше или же делая заказы в Интернет-магазинах. Здесь следует порекомендовать книжные магазины с книгами на русском языке в Варшаве и в Кракове (http://www.kulturarosyiska. com.pl), где можно приобрести учебные пособия, книги и словари, которые стоит использовать в процессе формирования социокультурной компетенции на занятиях по практикуму русской речи.

Учебные материалы можно найти также, например, на следующих сайтах:

http://www, ozon, ru/context/catalog/

http://shop.biblio-globus.ru/

http://www.mdk-arbat.ru/rkl.aspx http://www.ruthenia.ru/

http://www.flinta.ru/books.php?bs=5 http://author-edu.ru/dr info/

http://www.rus-lang.ru/ - сайт издательства „Русский язык” 
Мы предлагаем прежде всего использовать в процессе обучения РКИ следующие пособия, книги и словари:

1. Н.В. Баско, Изучаем русский, узнаем Россию. Учебное пособие по развитию речи, практической стилистике и культурологии. Серия: „Русский язык как иностранный". Издательства: Флинта, Наука, Москва 2005, 280 с.

2. Н.П. Вольская, Д.Б. Гудков, И.В. Захаренко, В.В. Красных, Можно? Нельзя? Практический минимум по культурной адаптации $b$ русской среде. Издательство: Русский язык. Курсы, Москва 2004, 48 с.

3. А.В. Сергеева, Русские. Стереотипы поведения, традиции, ментальность. Издательства: Флинта, Наука, Москва 2004, 328 с.

4. В.М. Соловьев, Тайны русской души. Вопросы. Ответы. Версии: книга для чтения о русском национальном характере для изучающих русский язык как иностранный. Издательство: Русский язык. Курсы, Москва 2009, 200 с.

5. Ю.Е. Прохоров, Россия. Большой лингвострановедческий словарь. Издательство АСТ-ПРЕСС, Москва 2009, 726 с.

Предлагаем также пособие Знакомимся с Россией, написанное автором настоящей статьи в соавторстве с М. Межвой³, которое предназначено для студентов II курса русской филологии, начинающих обучение русскому языку в вузе „с нуля". Это пособие направлено прежде всего на развитие социокультурной компетенции, а также самостоятельности, активности и коммуникативной компетенции студента.

Система образования в настоящее время нацелена не столько на усвоение суммы готовых знаний, сколько на формирование интеллектуальных умений и умений самостоятельной познавательной деятельности. Поэтому и содержание, и технологии обучения, и средства обучения меняются. Только учебника и учителя для формирования самостоятельности мышления, способности к рефлексии (размышлению, самонаблюдению, самооценке) недостаточно. Необходим широкий спектр информации, отражающей разные точки зрения на одну и ту же проблему, предоставляющей учащимся основу для размышлений, критического анализа, обобщений, самостоятельных выводов и решений. Роль Интернета в этом случае огромна. В образовательном процессе, в том числе в изучении РКИ, могут быть использованы основные функции Интернета, связанные с его вещательными, интерактивными и поисковыми услугами, а также с информационными ресурсами сети.

Вещательные услуги:

- книги, методическая литература, газеты, журналы в электронном виде;

${ }^{3}$ M. K o s s a k o w s k a - M a r a s, M. M i e r z w a, Знакомимся с Россией, Rzeszów 2009. 
- обучающие компьютерные программы;

- электронные библиотеки, базы данных, информационные системы;

- обучающие электронные книги, справочные файлы, словари, справочники.

Интерактивные услуги:

- электронная почта;

- электронные телеконференции;

- ire (internet relay chat).

Поисковые услуги:

- каталоги;

- поисковые системы;

- метапоисковые системы.

Среди информационных ресурсов сети следует выделить:

- курсы дистанционного обучения, размещаемые на отечественных образовательных серверах;

- курсы, интегрированные с системой очного базового, углубленного, углубленно-профильного обучения;

- полностью сетевые курсы;

- курсы, интегрированные с кейс-технологиями (печатными учебными пособиями, видеокассетами, CD-ROM дисками и пр.);

- курсы, программы, предназначенные для самообразования;

- веб-квесты, также предназначенные для целей обучения;

- обучающие олимпиады, викторины, телекоммуникационные проекты.

Интернет-ресурсы дают возможность использовать аутентичные страноведческие материалы, художественные тексты для чтения, а также материалы, ознакомляющие учащихся с повседневной жизнью россиян. На просторах всемирной паутины можно обнаружить множество специализированных форумов, где имеются подборки различных методических пособий, многочисленные советы и рекомендации, где собираются пользователи, заинтересованные в изучении данного языка и его культуры, и где можно обсудить ту или иную проблему.

Учащиеся имеют возможность воспользоваться дистанционными курсами русского языка как иностранного, а также разнообразными обучающими программами, которые преподносят необходимую для изучения информацию часто в виде игры или загадок. Коммуникационные технологии позволяют вести общение с иностранными друзьями на видео-чатах и в онлайн-разговорах.

Ниже приводятся примеры сайтов, которые можно дополнительно использовать в поисках разнообразной социокультурной информации.

Так, студентам следует знать основные сайты, необходимые каждому русисту: 
www.mapryal.org - МАПРЯЛ;

www.pushkin.edu.ru - сайт ИРЯ им. А.С. Пушкина;

www.gramota.ru - портал „Русский язык";

www.russkii.ru - справочная служба русского языка Института русского языка им. В.В. Виноградова РАН.

Интересную информацию можно найти и здесь:

http://www.coe.ru/ - информационный сайт Совета Европы в России, здесь можно ознакомиться, напр., с „Белой книгой” по межкультурному диалогу;

Сервер www.conradish.net - знакомство с русской литературой на русском и (частично) на английском языках;

www.russianedu.ru - журнал „Русский язык за рубежом";

http://www.russkiymir.ru/ru/magazine/ - журнал „Русский мир.Ru"; http://www.zlat-edu.ru - методические семинары, авторские мастер-классы авторов учебников;

www.langrus.ru - портал поддержки РКИ;

http://www.rudn.in7 или http://www.pfu.edu.ru/ - сайт РУДН, где много интересного и нужного для преподавателей РКИ;

http://www.tasteofrussian.com/ - изучение русского языка, записи в MP3; http://www.umopit.ru/RazgRuss.htm - тренажер-экзаменатор понимания разговорного русского языка. Бесплатная программа;

http://www.russianmentor.net - много различных упражнений, записей в MP3, текстов для чтения;

http://www1.voanews.com/russi an/news/ - „Голос Америки” по-русски, есть возможность читать на разных языках;

http://russia.edu.ru/ - сайт Министерства науки и образования Российской Федерации, проект „Российское образование для иностранных граждан";

http://www.tstu.ru/education/elib/pdf/2003/popoval.pdf - Т.В. Попова и др. Русский язык. Учебное пособие в двух частях для студентов-иностранцев подготовительного факультета, Часть вторая. Книга I, Тамбов 2003;

http://hello-world.com/Russian - изучение русского языка, сайт, предназначенный прежде всего для детей младшего школьного возраста; http://teachrussian.org/ - методичный ресурсный центр для преподавателей РКИ; http://www.deti.frn/towns.xml - „Детское радио”, он-лайн трансляция во всех странах мира;

http://old-rus.narod.ru/ - антология древнерусской литературы; http://allreferats.narod.ru/biball.htm - бесплатные сетевые библиотеки;

http://www.solnet.ee/ - сайт, предназначенный для детей младшего школьного возраста и их родителей; 
http://catalog.press.net.ru - каталог газет и журналов; www.molotok.ru - русская версия Аллегро; www.rutube.ru - русская версия Youtube; www.sokr.ru - то, что русские очень любят, т. е. сокращения; http://pietkaru.wordpress.com/ - интересные рассказы о России и не только, много юмора.

Ресурсы Интернета с дистанционными курсами русского языка: www.gwu.edu/ slavic/golosa - курс разговорной русской речи, видеоуроки, проверочные упражнения, курс для начинающих, но может подойти каждому, кто хочет проверить себя;

http://learningrussian.net/ - интересный курс русского яыка, видеоуроки, диалоги; www.masterrussian.com - курс русского языка;

www.linguarus.com - очень подробный курс русского языка, для филологов, к сожалению, без возможности прослушивания;

www.seelrc.org - курсы разных языков, не только русского;

http://www.russian-online.net/ - курсы русского языка для говорящих на немецком языке.

Курсы дистанционного обучения можно порекомендовать студентам, которые хотят повторить материал, найти что-то новое для себя или же проверить себя. Особенное внимание следует обратить на курсы, которые предоставляют возможность услышать русскую речь.

Нами указаны только некоторые сайты, которые могут быть использованы преподавателями и студентами. Использование поисковых систем в Интернете дает возможность находить уже существующие, а также постоянно появляющиеся новые сайты.

\section{2. Медиатека, библиотека, медиа-библиотека}

Важную роль в формировании социокультурной компетенции выполняет МЕДИАТЕКА, т. е. библиотека, отвечающая современному уровню, содержащая печатные издания (книги и периодику), аудиовизуальные и электронные материалы - компакт-диски, DVD, CD-ROM и информационные источники Интернета. Медиатека представляет собой электронный читальный зал, оснащенный современными компьютерами для работы с электронными библиотечными ресурсами. Право пользования медиатекой предоставляется пользователям, имеющим навыки работы с системой WINDOWS и пакетом Microsoft Office. Пользователь имеет право:

1. Осуществлять доступ к информационным образовательным ресурсам Интернета.

2. Работать с CD-ROMами из фонда медиатеки.

3. Использовать ресурсы локальной компьютерной сети: библиотечные электронные каталоги и картотеки, лицензионные ресурсы. 
4. Работать с текстовыми и графическими редакторами: MS Word, MS Excel, MS PowerPoint в рамках учебных задач.

5. Обращаться к сотрудникам справочно-библиографического отдела по вопросам работы с электронным каталогом.

6. Получить консультацию по работе с электронными информационными ресурсами образовательного характера из фонда медиатеки (on-line, CD-ROMы).

7. Копировать фрагменты документов на электронные носители у дежурного администратора.

8. Пользоваться дополнительными платными услугами: распечатывать информацию на принтере, сканировать и т. д.

В большинстве вузов в Польше существуют такие библиотеки. Необходимо поощрять студентов к пользованию ими в процессе подготовки самостоятельных заданий.

3. Кабинет, мультимедиа-лингафонный компьютерный класс

Обучение иностранному языку должно проходить в кабинете иностранного языка, который представляет собой либо: языковую лабораторию, оснащенную лингафонным устройством аудиоактивного типа, либо классное помещение, приспособленное для работы в малых группах, оснащенное классной доской, подвесным проекционным экраном (демонстрационной панелью) или интерактивной доской, которая работает как сенсорный компьютерный монитор. С помощью проектора на поверхность доски проецируется изображение компьютера - такое же, какое мы видим на обычном компьютерном мониторе. Доску можно использовать также в качестве маркерной доски или проекционного экрана.

Это может быть также мультимедиа-лингафонный компьютерный класс, оснащенный лингафонными устройствами, компьютерными и информационно-коммуникативными средствами обучения. К сожалению, оснащение вузов кабинетами в нужном количестве оставляет желать лучшего. Естественно, что такие компьютерные классы есть и их число постоянно растет, однако, к сожалению, часто единственным средством, которым может воспользоваться преподаватель, является обыкновенный магнитофон.

\section{Средства, связанные с языковой парасредой}

Размеры настоящей статьи не дают возможности подробно описать все средства языковой парасреды, поэтому обратим внимание только на факт, что средства, связанные с языковой парасредой, в эпоху информатики и в связи с применением новых средств коммуникации также могут распространяться при помощи Интернета. 
Нельзя не обратить внимания на то, что учителя / преподаватели часто обладают аутентичными журналами и газетами, которые можно полистать, предметами быта, которые можно взять в руки, старыми письмами, к которым можно прикоснуться. Естественно, что возможность этого рода непосредственного контакта весьма ценна и ничем не заменима.

Просмотр русского фильма без перевода, прослушание аудиозаписи, не предназначенной специально для изучающих РКИ, прослушание песни, которая на данный момент является очень популярной в России, а еще лучше - прослушание группы поющих русских студентов - в очень большой степени повышают уровень развития социокультурной и межкультурной компетенции.

Следует обратить внимание, что возможности использования различных средств студентами зависят от:

- самостоятельности (при высоком уровне самостоятельности студент пользуется большим количеством средств);

- степени владения языком (низкий уровень знания языка не создает слишком много возможностей для использования различных средств);

- возраста учащихся (взрослый учащийся может постоянно находить что-то новое);

- мотивации (высокий уровень мотивации влияет на большое количество используемых средств);

- цели (наличие конкретной цели влечет за собой использование определенных, нужных учащемуся, средств).

В заключение следует подчеркнуть, что правильно подобранные средства повышают уровень социокультурной компетенции, наличие которой является необходимым элементом личности учащегося в эпоху информационно-коммуникативной технологии. 